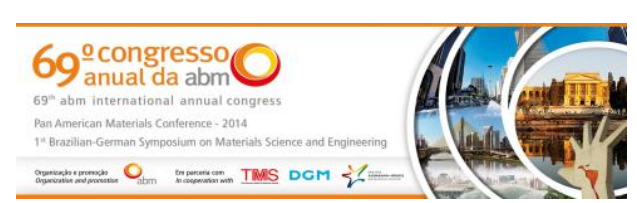

Tema: Forjamento

\title{
ESTUDO EXPERIMENTAL PARA FORJAMENTO A QUENTE EM MATRIZ FECHADA DE PEÇAS DE MÉDIA COMPLEXIDADE*
}

\author{
Angela Selau Marques ${ }^{1}$ \\ Luana De Lucca de Costa ${ }^{2}$ \\ Vinicius Martins ${ }^{3}$ \\ Lírio Schaeffer ${ }^{4}$
}

\section{Resumo}

A ferramenta CAE possibilita a avaliação do processo de forjamento virtualmente para otimização da produção industrial reduzindo o custo final do produto através do mínimo uso de matéria prima, juntamente com a previsão das variáveis que ocorrem durante a conformação do material no processo. Os procedimentos necessários para o forjamento de uma peça com geometria de média complexidade forjada em alumínio é apresentada. $O$ objetivo deste trabalho é analisar experimentalmente 0 forjamento desta e compara-la com a simulação computacional.

Palavras-chave: Forjamento; Simulação; CAE/CAD/CAM.

\section{EXPERIMENTAL STUDY FOR HOT FORGING IN CLOSED DIES FOR A PIECE WITH MEDIUM COMPLEXITY}

\begin{abstract}
CAE tools allow the evaluation of the forging process virtually for optimization of industrial production by reducing the final cost of the product through the minimal use of raw materials, along with the prediction of the variables that occur during the forming of the material in the process. The procedures required for the forging of a workpiece with medium complexity forged aluminum geometry is presented. The objective of this work is to analyze forging experimentally and compare it with the numerical/computer simulation
\end{abstract}

Keywords: Forging; Simulation; CAE/CAD/CAM.

1 Tecnóloga em Fabricação Mecânica, Mestranda, Programa de Pós-Graduação em Engenharia de Minas, Metalúrgica e Materiais (PPGEM), Laboratório de Transformação Mecânica (LdTM), Departamento de Metalurgia, UFRGS, Porto Alegre, RS, Brasil; angela_selau@ufrgs.br

2 Engenheira Mecânica, Mestranda, PPGEM, LdTM, Departamento de Metalurgia, UFRGS, Porto Alegre, RS, Brasil; luana.lucca@ufrgs.br

3 Professor, Instituto Federal Sul Rio-Grandense (IFSul), Campus Sapucaia do Sul, Doutorando, PPGEM, LdTM, Depto. de Metalurgia, UFRGS, Porto Alegre, RS, Brasil; viniciushiper@yahoo.com.br.

4 Prof. Dr. -Ing., Coordenador do Laboratório de Transformação Mecânica (LdTM), Departamento de Metalurgia, PPGEM, UFRGS, Porto Alegre, RS, Brasil; schaefer@ufrgs.br.

\footnotetext{
* Contribuição técnica ao 69ำ Congresso Anual da ABM - Internacional e ao 14ํㅡㄹ ENEMET - Encontro Nacional de Estudantes de Engenharia Metalúrgica, de Materiais e de Minas, 21 a 25 de julho de 2014, São Paulo, SP, Brasil.
} 
processo. Em meados da década de 90, a maioria dos programas possibilitava a simulação do processo de forjamento para peças de simetria axial e outras onde o fluxo de material pudesse ser aproximado como ocorrendo em apenas duas dimensões (deformação plana) [5].

Atualmente, pode-se dizer que os programas de simulação tornaram-se uma ferramenta prática e essencial para o desenvolvimento e otimização da tecnologia de processos de deformação plástica. Inúmeros programas comerciais, baseados em diferentes métodos de solução, estão disponíveis no mercado. Os métodos de solução mais empregados são elementos finitos e volumes finitos [6].

\subsubsection{Método de solução numérica}

A maioria dos softwares permite ao usuário escolher o método de solução numérica que será utilizado na simulação. Os principais métodos utilizados atualmente são o Método de Elementos Finitos e o Método dos Volumes Finitos [7].

Para realizar a simulação numérica, a peça é discretizada, ou seja, ocorre uma divisão do volume da peça a ser analisada em um número finito de volumes, ou elementos, formando uma malha. Normalmente, essa malha é constituída, no caso bidimensional, de triângulos ou quadriláteros, cujos vértices são denominados nós da malha. A simulação do deslocamento das matrizes é dividida em pequenos incrementos de deslocamento. Cálculos são então realizados até que um balanço entre as forças internas e externas seja atingido e, após, um novo incremento de deslocamento é realizado. Este processo é repetido até o final da simulação. A mudança de forma envolvida no processo de forjamento geralmente causa grande deformação da malha e, dependendo das capacidades do hardware e do software, pode levar dias até se obter um resultado final satisfatório [8].

\section{MATERIAIS E MÉTODOS}

\subsection{Geometria da Peça em Estudo}

A geometria da peça está representada na Figura 2 através da modelagem em 3D da peça desenvolvida no software SolidWorks. A utilização deste sistema permitiu uma série de automatizações com relação à modelagem da peça, da geratriz e das matrizes. Pois, a partir do momento em que a peça está modelada no SolidWorks pode-se desenvolver todo ferramental de forma simplificada. Todavia, a característica deste sistema que mais contribui nesta etapa da pesquisa é a possibilidade de alterar facilmente qualquer medida da peça, sendo que estas alterações se regeneram de forma automática de acordo com as novas dimensões atribuídas.

\footnotetext{
* Contribuição técnica ao $69^{\circ}$ Congresso Anual da ABM - Internacional e ao 14ํㅡㄹ ENEMET - Encontro Nacional de Estudantes de Engenharia Metalúrgica, de Materiais e de Minas, 21 a 25 de julho de 2014, São Paulo, SP, Brasil.
} 

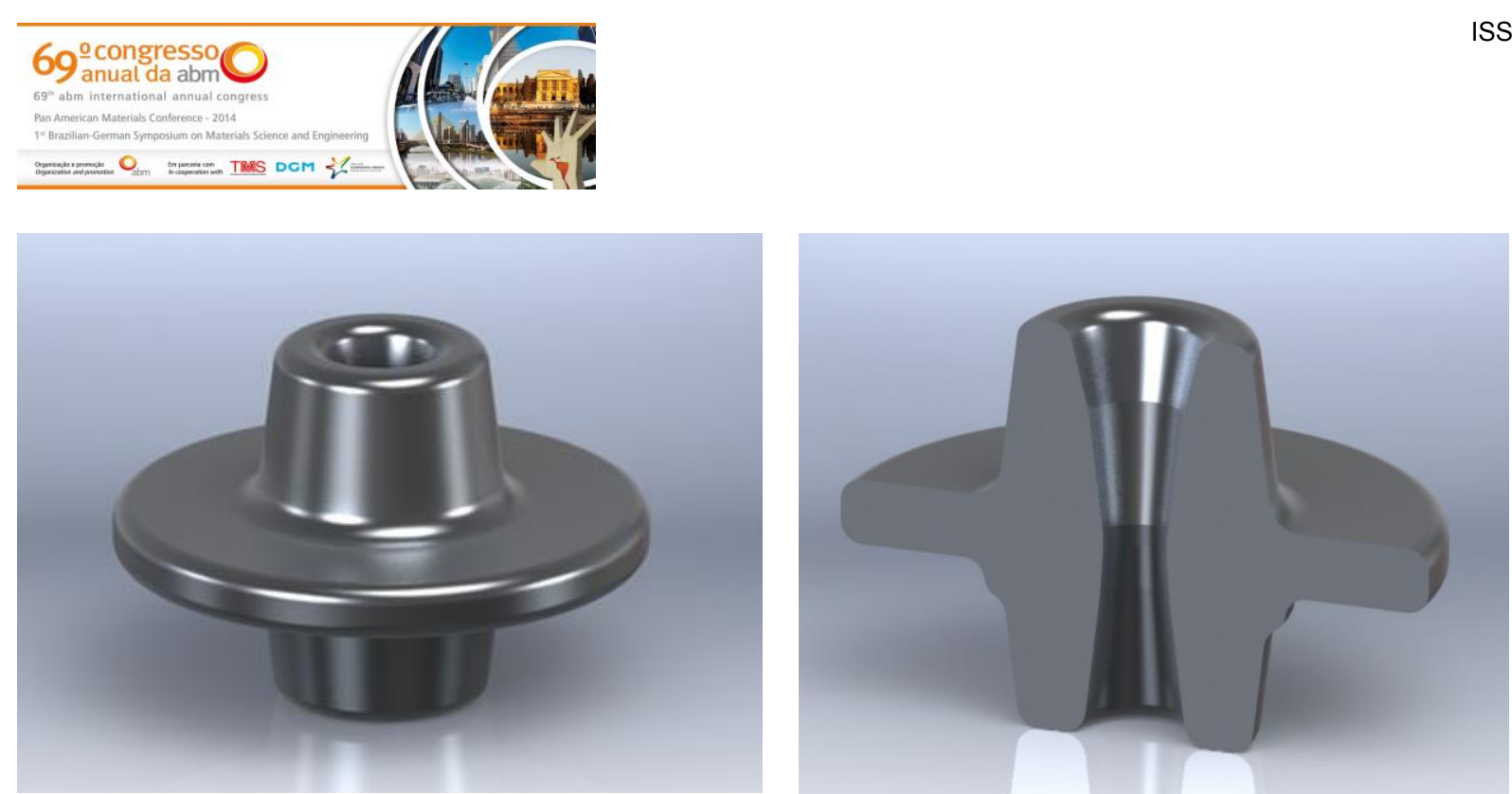

Figura 2. Representação 3D da peça a ser forjada

A Figura 3 ilustra as principais cotas da peça. As paredes da peça foram projetadas com ângulos de saída de 7º, a literatura descrita por Schaeffer [9] indica no mínimo $6^{\circ}$, porém devido à geometria da peça apresentar, principalmente na região interna, probabilidade de adesão peça/ferramenta optou-se por um ângulo maior.

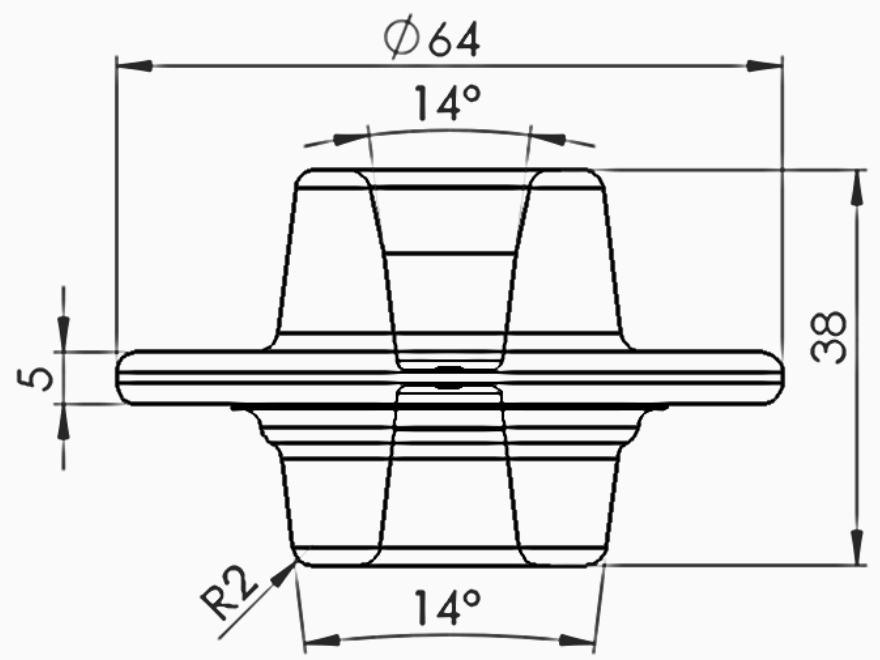

Figura 3. Principais cotas da peça de trabalho, em milímetros

Para uma representação virtual da peça forjada desenhou-se uma aproximação do que poderia ficar de rebarba na peça, desta forma foi possível estimar, pela lei da conservação do volume as dimensões da geratriz inicial.

A geratriz foi dimensionada de forma a ter o mesmo volume da peça a ser forjada e considerando o adicional referente à rebarba. Assim, as dimensões do billet cilíndrico vazado, são: altura de $35,5 \mathrm{~mm}$, largura de $41,5 \mathrm{~mm}$, com furo concêntrico passante de $12 \mathrm{~mm}$ de diâmetro. As dimensões do billet maciço são: altura de $32,02 \mathrm{~mm}$, largura de $41,5 \mathrm{~mm}$.

Os desenhos do canal e do poço de rebarba são necessários também para que se possa desenvolver o projeto do ferramental. A Figura 4 mostra uma vista em corte da matriz superior e inferior, bem como, o canal para saída de gás, a cavidade dos pinos guias, o canal de rebarba e uma representação da peça idealizada:

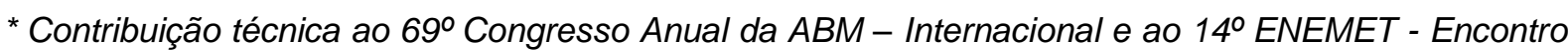
Nacional de Estudantes de Engenharia Metalúrgica, de Materiais e de Minas, 21 a 25 de julho de 2014, São Paulo, SP, Brasil.
} 


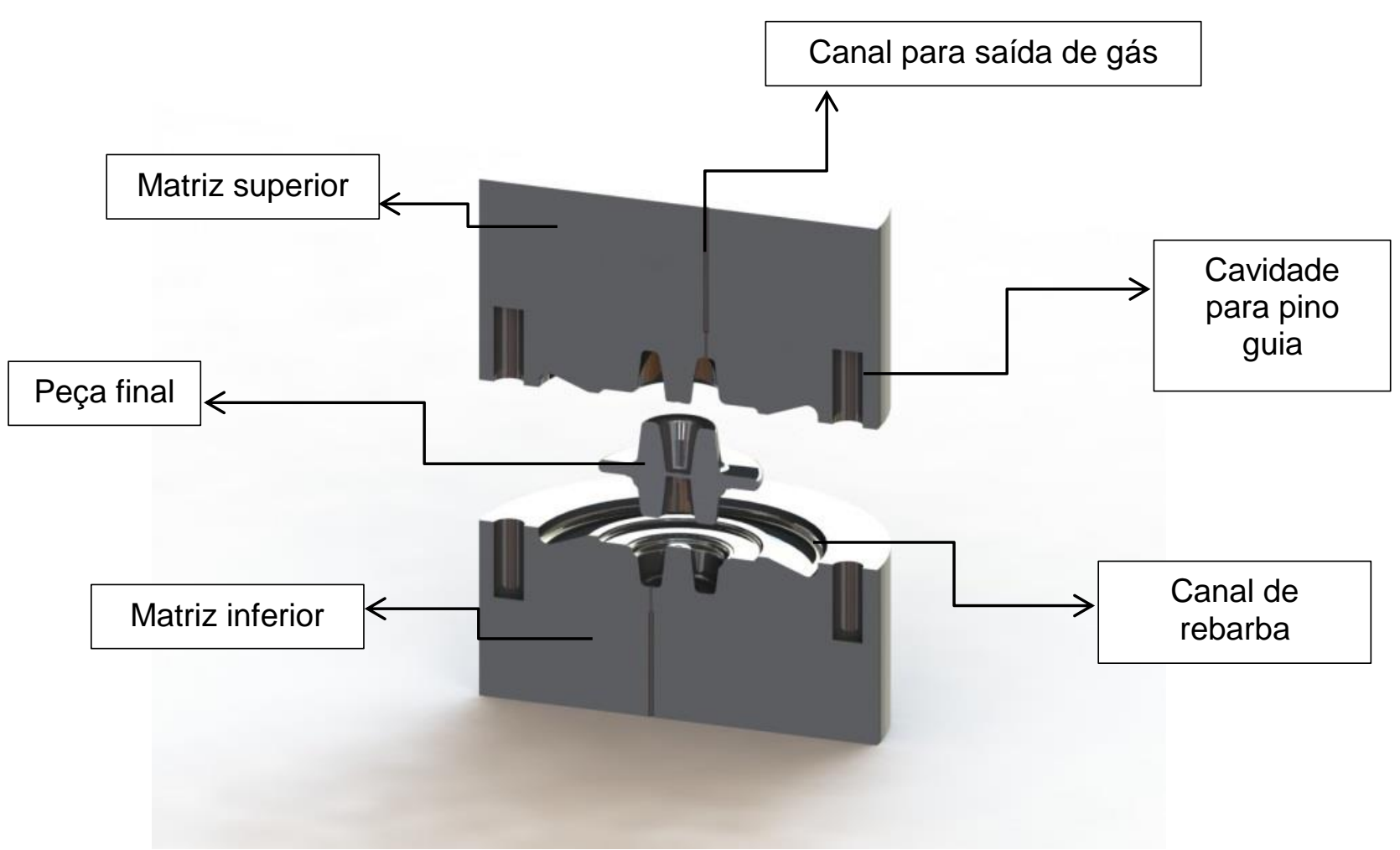

Figura 4. Projeto da matriz inferior e superior

\subsection{Simulação Numérica do processo forjamento}

A simulação do processo de forjamento é utilizada para avaliar o preenchimento do molde e a fabricação de peças dentro das especificações. Além disso, também são analisados parâmetros envolvidos no processo, tais como: geometria do billet, geometria da matriz e dos canais de rebarba, força de forjamento, temperatura, atrito, entre outros. Através dos resultados apresentados pela simulação pôde-se verificar se a peça forjada será obtida livre de defeitos.

O método de elemento finito foi o escolhido para analisar o processo de forjamento, devido à geometria da peça, utilizou-se a simulação em 3D, cujos resultados são mais confiáveis e adequados para o forjamento a quente, conforme indica a literatura apresentada pelo fabricante do software e pesquisas realizadas [10].

A escolha pelo método utilizado é definida ao iniciarem-se os trabalhos com o Simufact. Além disso, nesta etapa é definido o tipo de processo, por exemplo, se o forjamento será a quente ou o frio, e a quantidade de matrizes utilizadas na simulação.

O tamanho de malha, o tipo e o número de elementos gerados pelo software, influenciam diretamente nos resultados apresentados pela simulação [8]. A malha mais refinada com maior quantidade de elementos resulta em um tempo maior para resolução dos cálculos. Por isso, é necessário que se encontre um equilíbrio entre estes fatores.

Foram realizadas simulações com dois tipos de malha, 2D e 3D, determinou-se que a melhor malha a ser utilizada é a 3D, pois esta apresenta resultados satisfatórios. Sendo assim, utilizou-se uma malha de $1 \mathrm{~mm}$, o tipo de elemento é o hexaédrico e o número de elementos gerados foi de 15484. Na Figura 5 é possível identificar a malha gerada.

\footnotetext{
* Contribuição técnica ao $69^{\circ}$ Congresso Anual da ABM - Internacional e ao 14ํㅡㄹ ENEMET - Encontro Nacional de Estudantes de Engenharia Metalúrgica, de Materiais e de Minas, 21 a 25 de julho de 2014, São Paulo, SP, Brasil.
} 


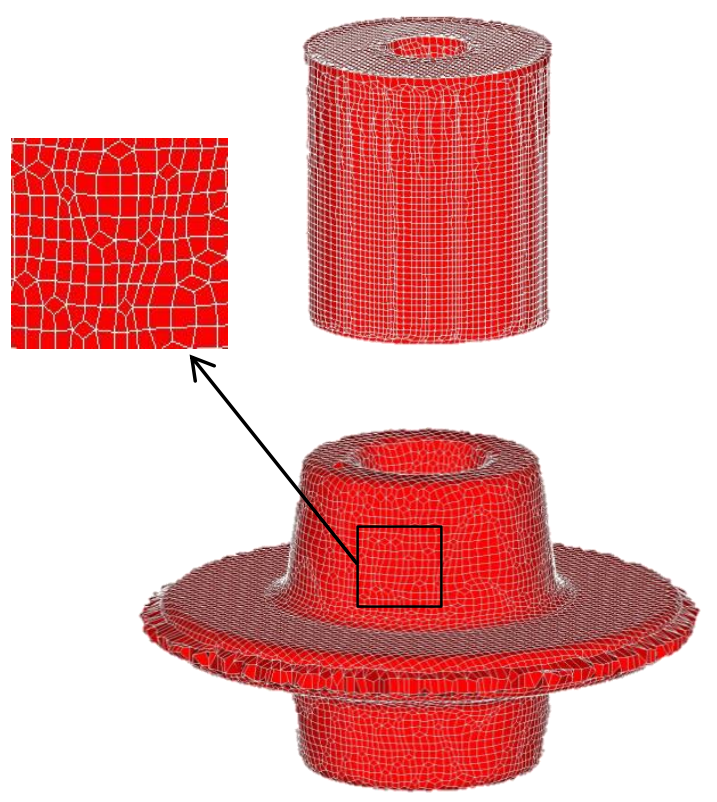

(a)

Figura 5. Malha da peça com billet vazada

\subsubsection{Parâmetros empregados na simulação}

Os parâmetros utilizados são de grande importância para um resultado confiável da simulação. Utilizaram-se os seguintes dados de entrada:

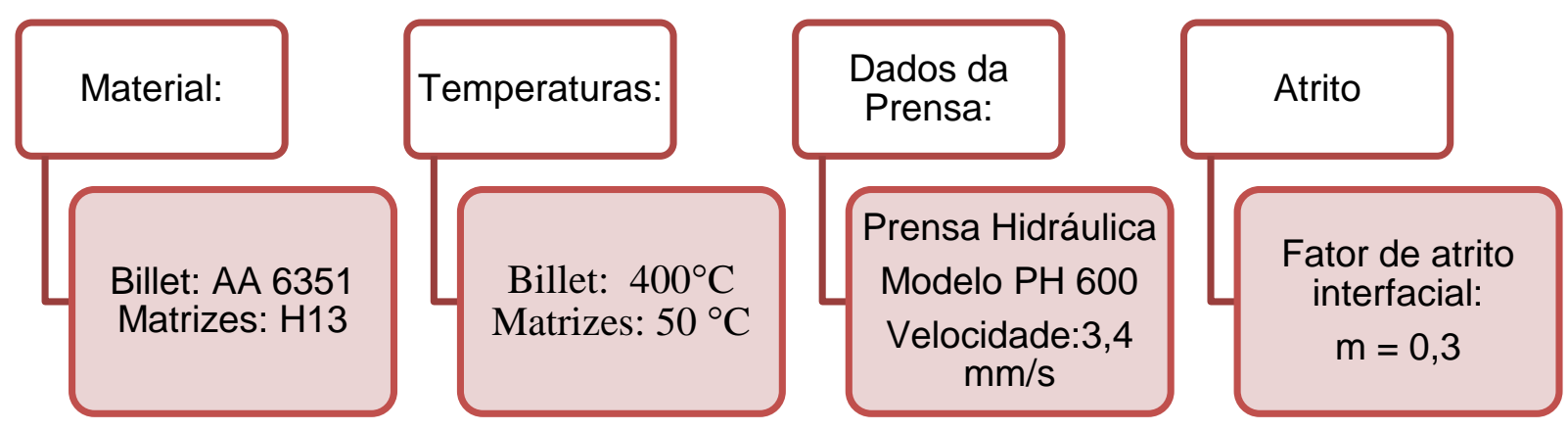

\subsubsection{Descrição do processo experimental de forjamento}

Após a realização da simulação e a fabricação do ferramental fez-se o forjamento da peça. Os mesmos parâmetros da simulação foram utilizados no intuito de comparar os resultados obtidos na simulação numérica e dados analíticos com os experimentos realizados.

Para o forjamento da peça em estudo utilizou-se uma prensa hidráulica da marca FKL, a qual possui capacidade de força de 600 toneladas e velocidade de prensagem de $3,4 \mathrm{~mm} / \mathrm{s}$. A unidade hidráulica desta máquina é instalada na parte superior. O sistema hidráulico é constituído basicamente por tanque, bombas, válvulas direcionais, cilindro principal, cilindros auxiliares e válvula de preenchimento. A válvula de preenchimento é uma válvula de retenção pilotada, montada sobre o cilindro principal como a função de abrir o mesmo para movimentações rápidas. A Figura 6 apresenta o equipamento supracitado.

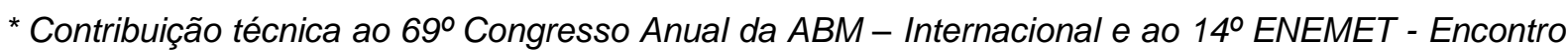
Nacional de Estudantes de Engenharia Metalúrgica, de Materiais e de Minas, 21 a 25 de julho de 2014, São Paulo, SP, Brasil.
} 

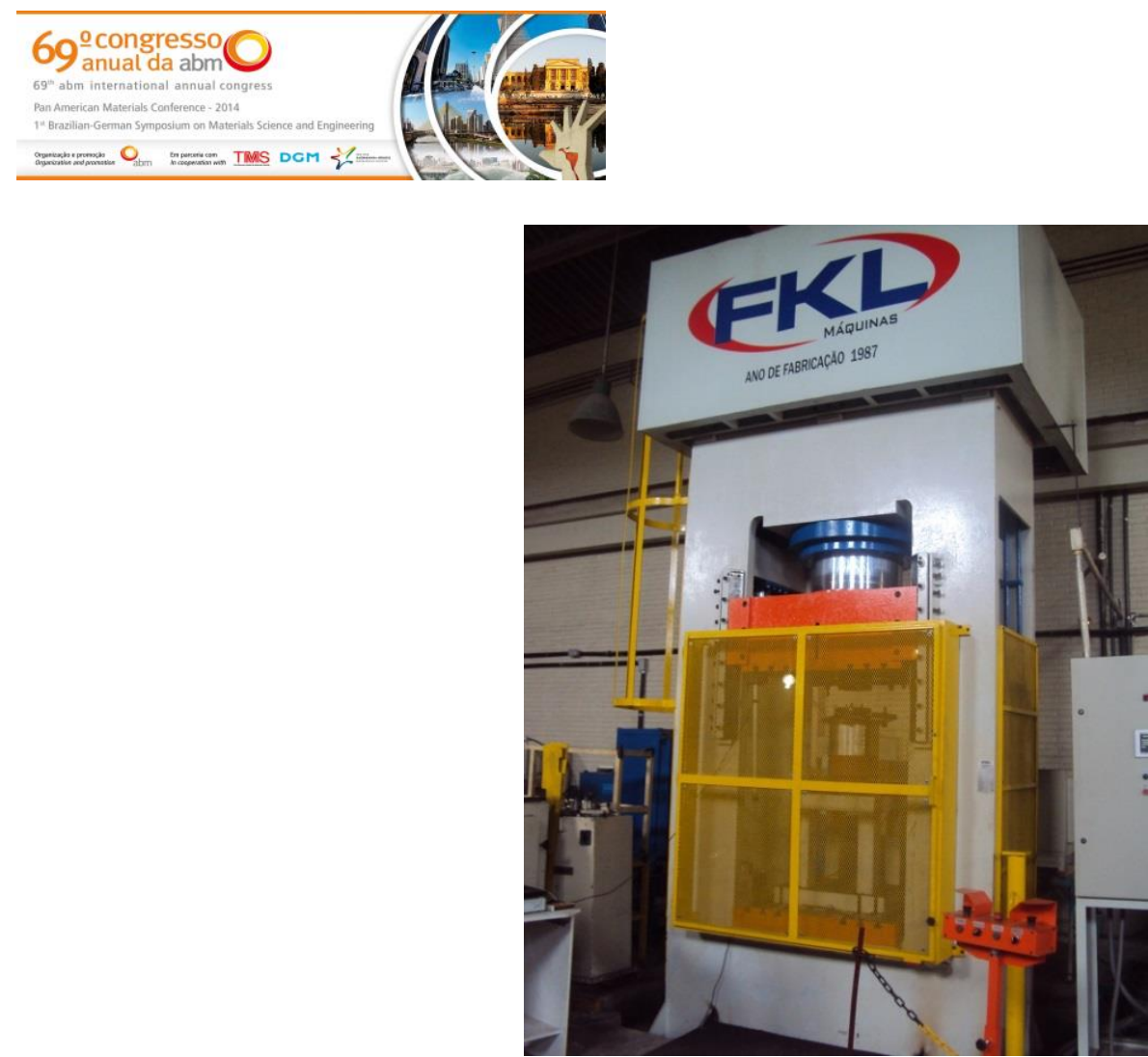

Figura 6. Prensa hidráulica de 600ton, marca FKL

A configuração dos parâmetros da máquina para o funcionamento dela é feito através de um sistema chamado de IHM da marca Siemens. A partir desta interface, é possível acessar e modificar todos os valores programáveis da máquina.

As matrizes são fixadas à máquina com grampos apropriados para evitar a ocorrência de movimentos relativos entre as matrizes durante o processo de forjamento. As ferramentas possuem pinos guias para evitar o deslocamento durante a conformação. Elas são aquecidas através do contato com um tarugo de aço aquecido a $300^{\circ} \mathrm{C}$.

Aqueceram-se os billets a uma temperatura de $400^{\circ} \mathrm{C}$, em um forno elétrico, da marca Sanchis. Na sequência eles foram mergulhados em solução lubrificante sintética a fim de obter-se uma película lubrificante envolvendo os tarugos. $O$ forno de aquecimento está posicionado ao lado da prensa, a fim de, reduzir a distância e o tempo de movimentação do billet aquecido até a prensa, evitando assim, a perda de calor.

As matrizes também foram lubrificadas. Borrifou-se sobre a superfície da mesma uma solução lubrificante sintética, conforme Figura 7 Para aquecer as matrizes utilizou-se um tarugo pré-aquecido o qual foi colocado em contato com a matriz.

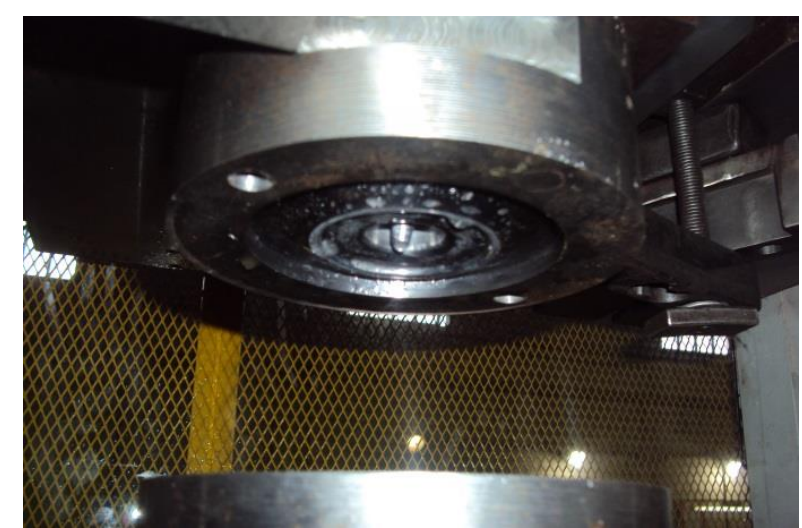

Figura 7. Matriz lubrificada

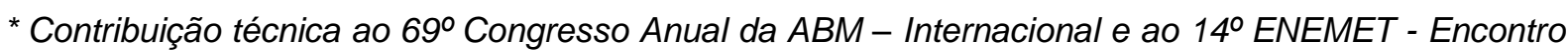
Nacional de Estudantes de Engenharia Metalúrgica, de Materiais e de Minas, 21 a 25 de julho de 2014, São Paulo, SP, Brasil.
} 


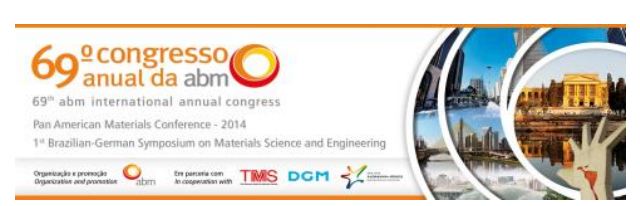

Após a alteração das dimensões do billet a simulação numérica computacional não apresentou qualquer ponto de falha de preenchimento, apontando que toda a superfície da cavidade da ferramenta entrou em contato com o material (AA 6351).

Em relação à temperatura do processo e sua evolução durante a deformação imposta, nota-se que a região próxima ao canal de rebarba é a que mantém a temperatura mais elevada, pois é a que sofre maior deformação e atrito, e, além disso, a última parte da peça que entra em contato com a matriz. A Figura 10 exibe a distribuição das temperaturas atingidas no final do forjamento.

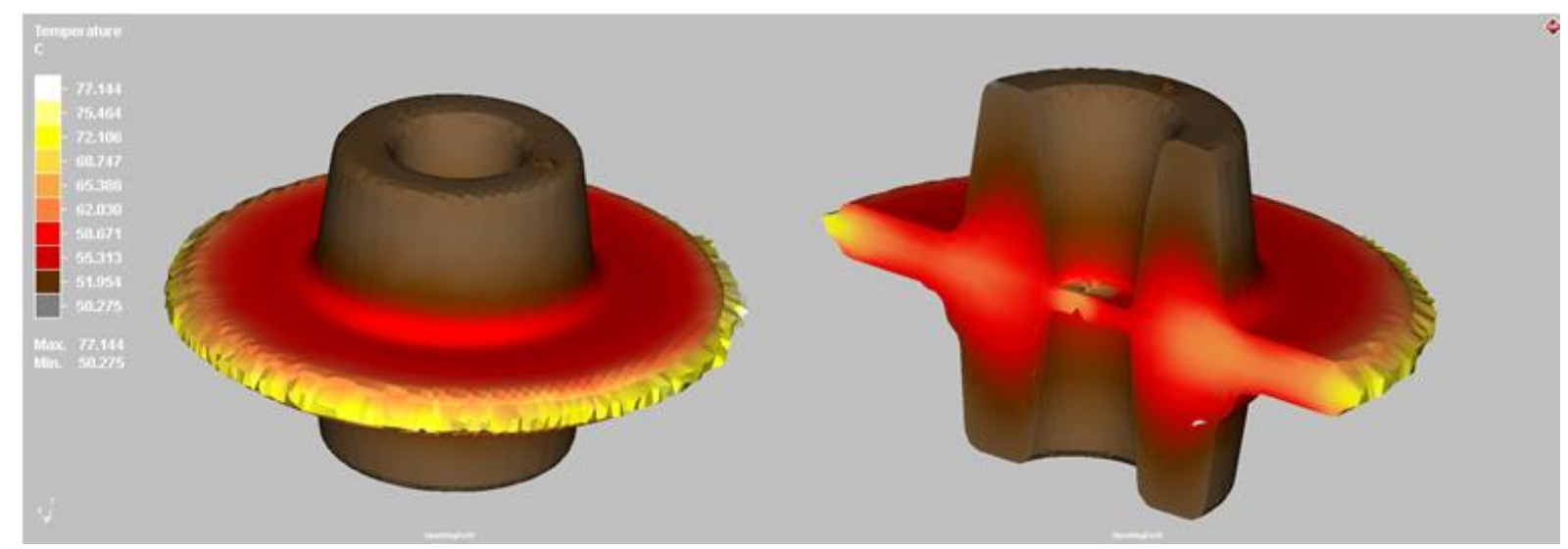

Figura 10. Distribuição de temperaturas

Pode se perceber que a temperatura mais baixa está localizada na parte superior e inferior da peça. Nestas regiões, a temperatura se manteve constante e em torno de $50^{\circ} \mathrm{C}$, ou seja, apresentou resfriamento rápido devido a menor espessura e maior área de contato com a matriz. A maior temperatura é encontrada na entrada do canal de rebarba, região onde também se localiza a maior velocidade de deformação do processo. Nestas regiões, a temperatura mantém-se em torno de $70^{\circ} \mathrm{C}$.

A deformação foi efetuada em uma única e contínua etapa de conformação. As regiões, representadas pela cor vermelha no software Simufact.Forming são as que apresentam maior deformação conforme mostra a Figura 11.

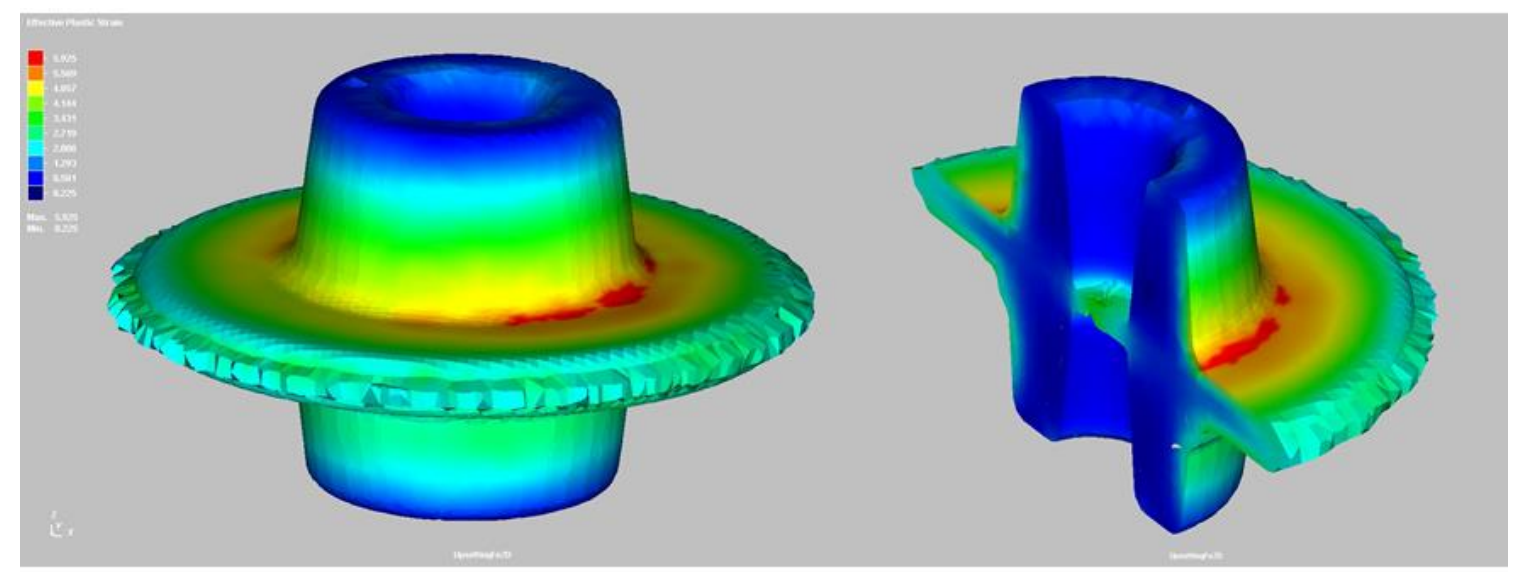

Figura 11. Deformação plástica

Observa-se que a deformação se distribui de forma heterogênea na secção da barra. De acordo com a Figura 12 região que apresenta a maior concentração de

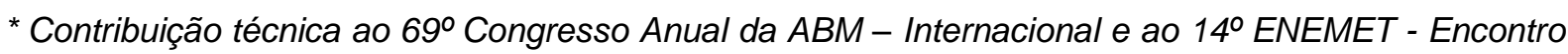
Nacional de Estudantes de Engenharia Metalúrgica, de Materiais e de Minas, 21 a 25 de julho de 2014, São Paulo, SP, Brasil.
} 


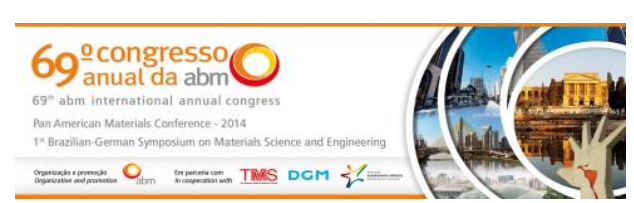

tensão é a mesma que o material sofre maior deformação. Isso acontece porque neste local o fluxo do material é forçado a mudar de sentido.

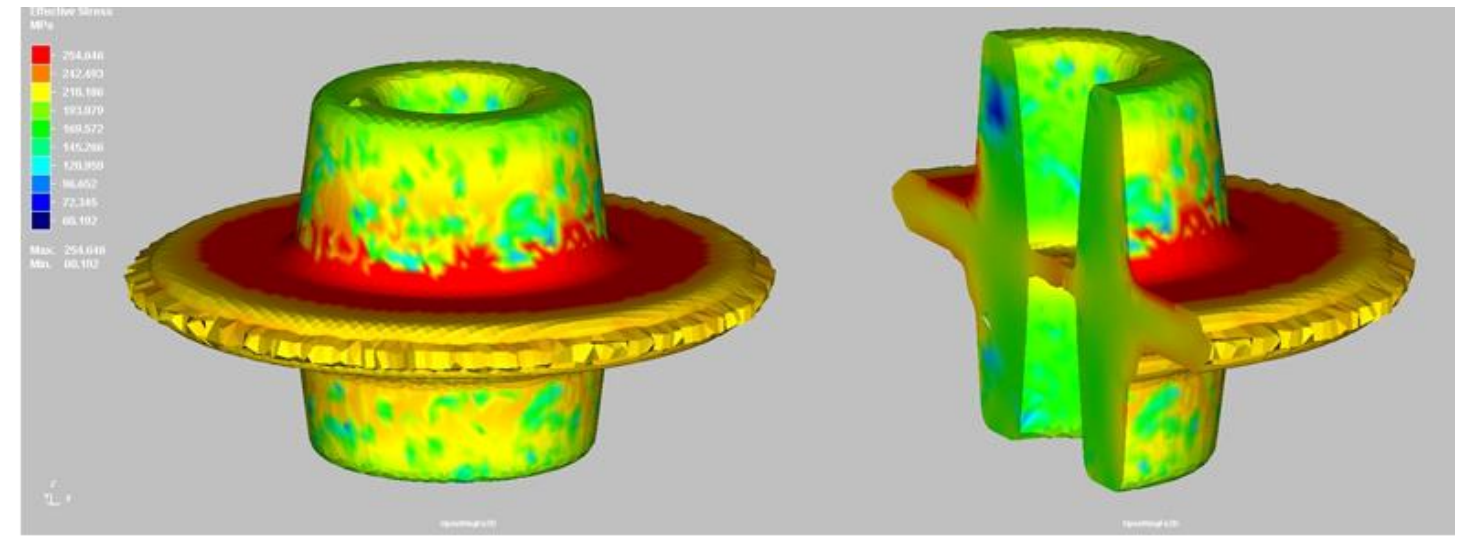

Figura 12. Distribuição da tensão

A Figura 13 (a) permite a visualização das linhas de fluxo do material obtidas na simulação. Através de uma análise macrografica da Figura 13 (b) revela-se 0 fibramento da peça forjada, através da qual pode-se verificar que o escoamento do material ocorreu de forma similar ao ocorrido na simulação.

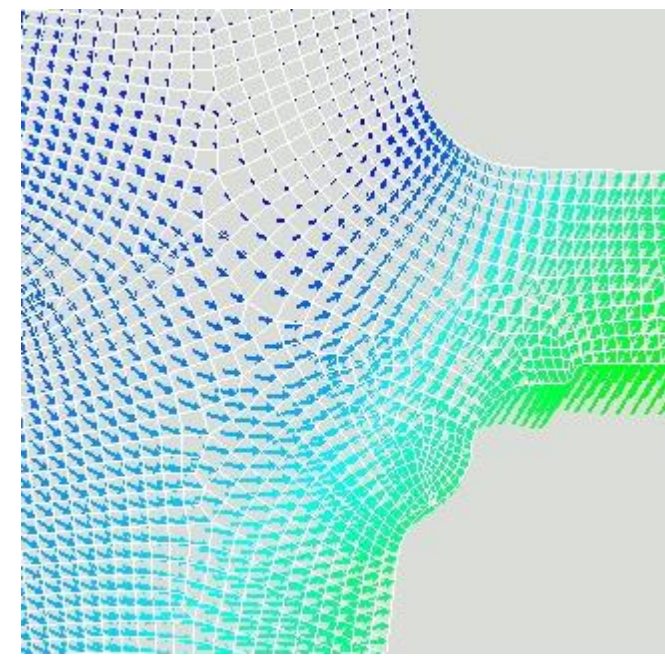

(a)

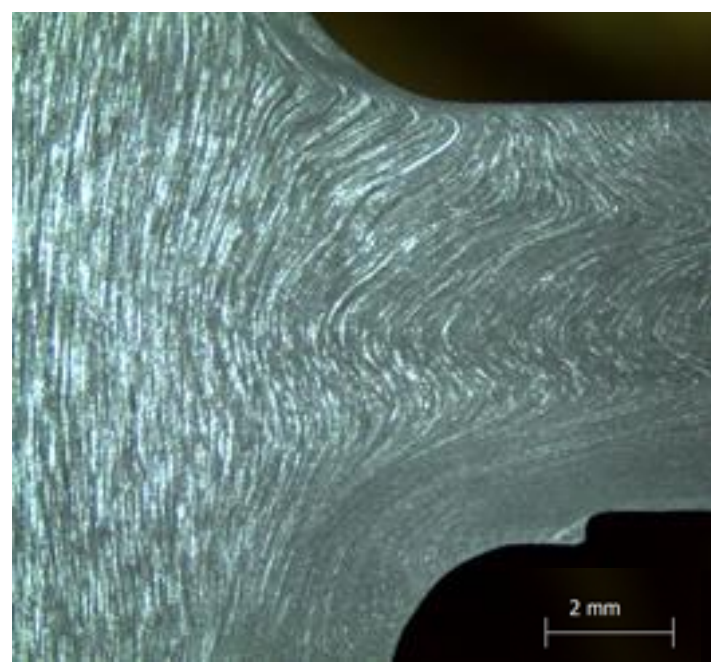

(b)

Figura 13. Comparação do escoamento do material. Simulação versus Real

Em relação à força de forjamento, foram simulados duas condições de processamento, todas elas considerando-se uma deformação em etapa única. A força necessária para o forjamento, da peça com billet vazado, obtida na simulação computacional numérica foi de $2432,05 \mathrm{kN}$.

A força necessária para o forjamento da peça com billet maciço, que é de $2814,51 \mathrm{kN}$. É possível perceber que no inicio do processo a força elevou-se de forma abrupta, que é quando o material do billet é forçado a escoar para a lateral da peça. Diferente do que acontece com o billet vazado no qual a força eleva-se de forma constante e aumenta mais significativa apenas no final do processo, durante 0 preenchimento do canal de rebarba.

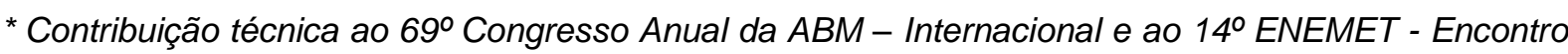
Nacional de Estudantes de Engenharia Metalúrgica, de Materiais e de Minas, 21 a 25 de julho de 2014, São Paulo, SP, Brasil.
} 


\subsection{Análise Experimental}

A primeira dificuldade encontrada durante o forjamento da peça, e não previsto pela simulação, foi fazer o posicionamento correto do billet sobre a matriz. Para que o material escoe de maneira uniforme é necessário centralizar o billet na matriz no inicio do processo. Em função disso, o material escoou de forma desuniforme dentro da cavidade, provocando a deformação no pino central da matriz. A Figura 14 mostra exemplo destes problemas.

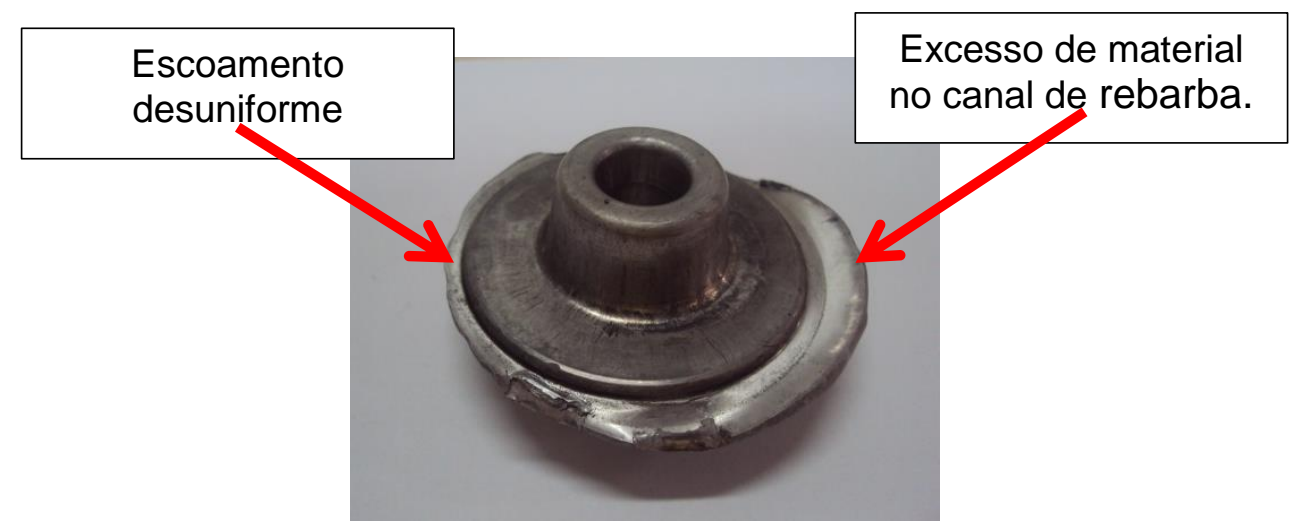

Figura 14. Primeiro experimento: Escoamento desuniforme

Além disso, as peças fabricadas no primeiro experimento não preencheram totalmente a cavidade da matriz, conforme a Figura 15. Este problema ocorreu principalmente em função da liberação de gases do material. Assim sendo, os dados de força obtidos neste primeiro experimento foram desconsiderados.

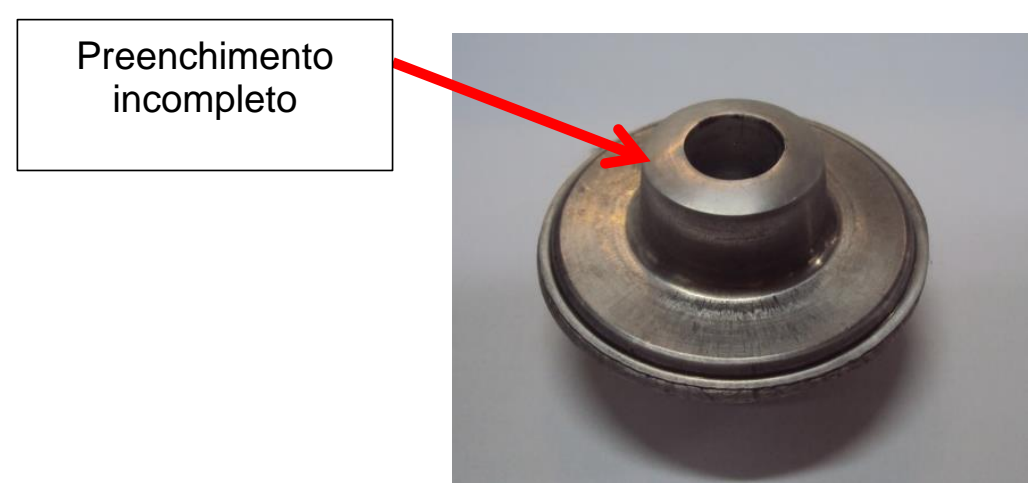

Figura 15. Primeiro experimento: Preenchimento incompleto

Para o forjamento da peça com billet maciço, foi necessário um billet maior do que o calculado utilizando a lei de constância de volume, pois o material exibe resistência em escoar na direção de preenchimento da matriz superior escoando com maior facilidade para o canal de rebarba.

Realizou-se então um segundo forjamento, no qual corrigiu-se os problemas encontrados. Para facilitar o posicionamento do billet na matriz inseriu-se um pequeno rebaixo de $0,5 \mathrm{~mm}$, desta forma o billet permanece sempre na mesma posição. Para facilitar a saída dos gases, liberados pelo material ao ser aquecido, inseriu-se um furo com diâmetro de $1 \mathrm{~mm}$ em cada uma das matrizes, conforme mostra a Figura 16.

\footnotetext{
* Contribuição técnica ao 69ำ Congresso Anual da ABM - Internacional e ao 14ํㅡㄹ ENEMET - Encontro Nacional de Estudantes de Engenharia Metalúrgica, de Materiais e de Minas, 21 a 25 de julho de 2014, São Paulo, SP, Brasil.
} 


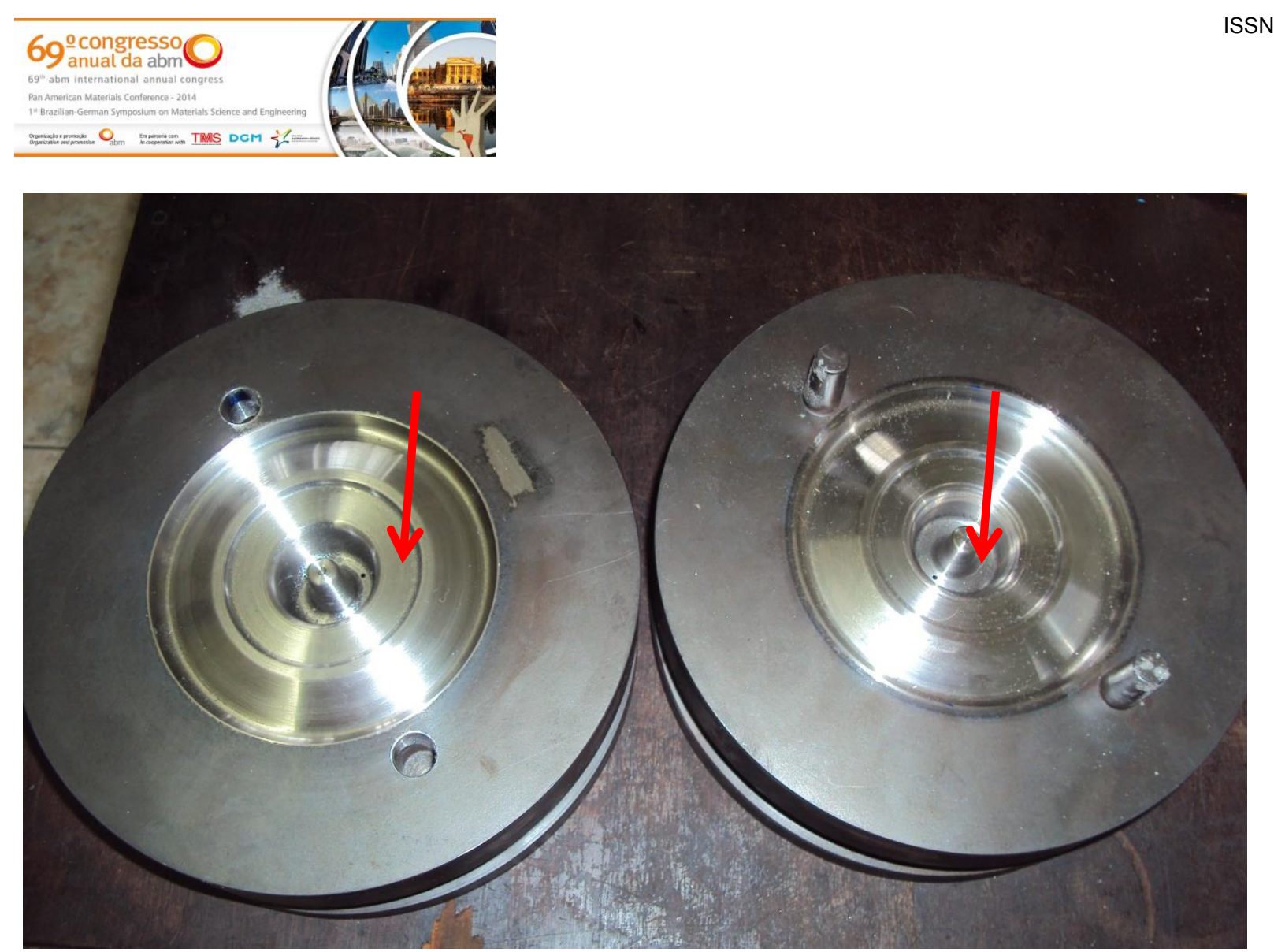

Figura 16. Furos para escape de gases

A Figura 17 mostra as peças forjadas, com os billets vazados e maciços. Após análise visual das peças, concluiu-se que é possível fabricar peças isentas de defeitos e trincas.

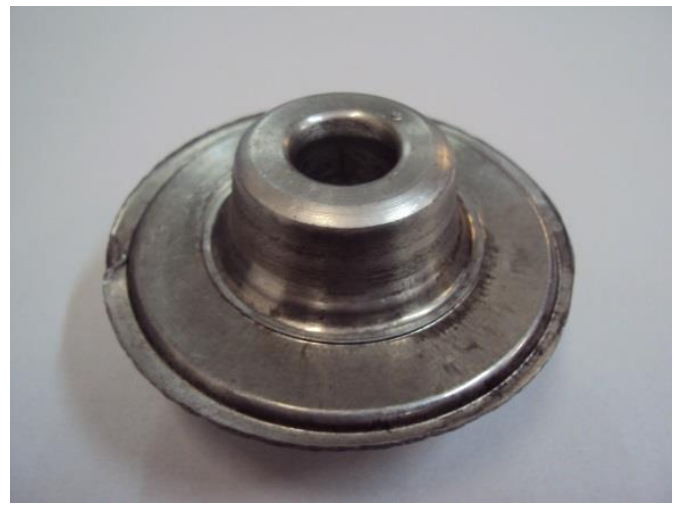

(a) Experimento com billet vazado

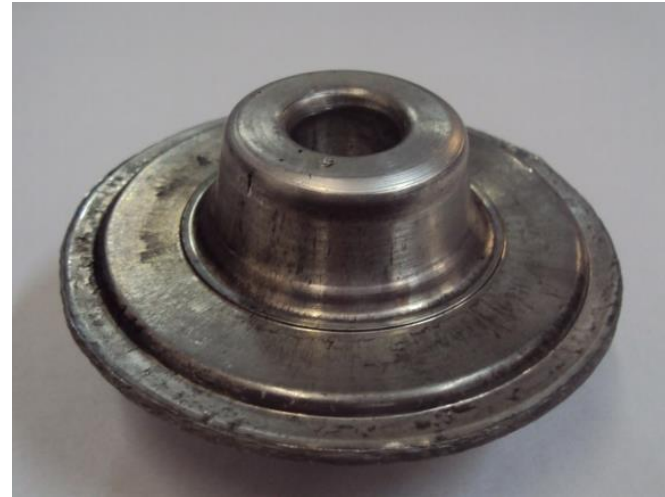

(b) Experimento com billet maciço

Figura 17. Peças forjadas

Após o forjamento, uma peça foi submetida a um ensaio metálografico, para revelar sua macrografia. Após o corte da peça e o polimento um reagente, chamado de Água Régia foi aplicado sobre a seção em estudo com o auxílio de um chumaço de algodão. A Figura 18 apresenta a macroestrutura, evidenciando as linhas de fluxo do material durante a conformação.

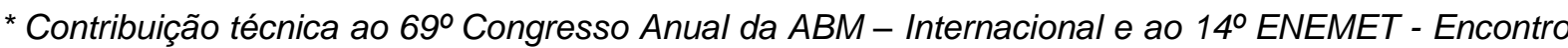
Nacional de Estudantes de Engenharia Metalúrgica, de Materiais e de Minas, 21 a 25 de julho de 2014, São Paulo, SP, Brasil.
} 


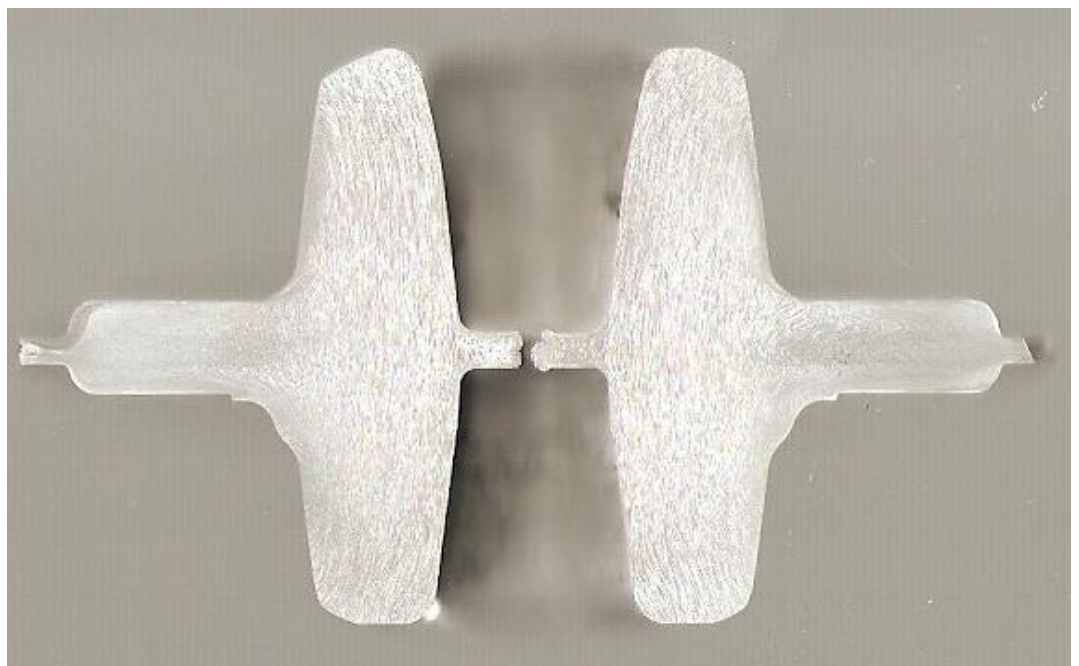

Figura 18. Macrografia

No forjamento experimental a força total constatada pela célula de carga foi de aproximadamente $3432,33 \mathrm{kN}$ (350 toneladas) para o billet maciço e de 2451,66 kN (250 toneladas) para o billet vazado, conforme mostram as Figuras 19 e 20.

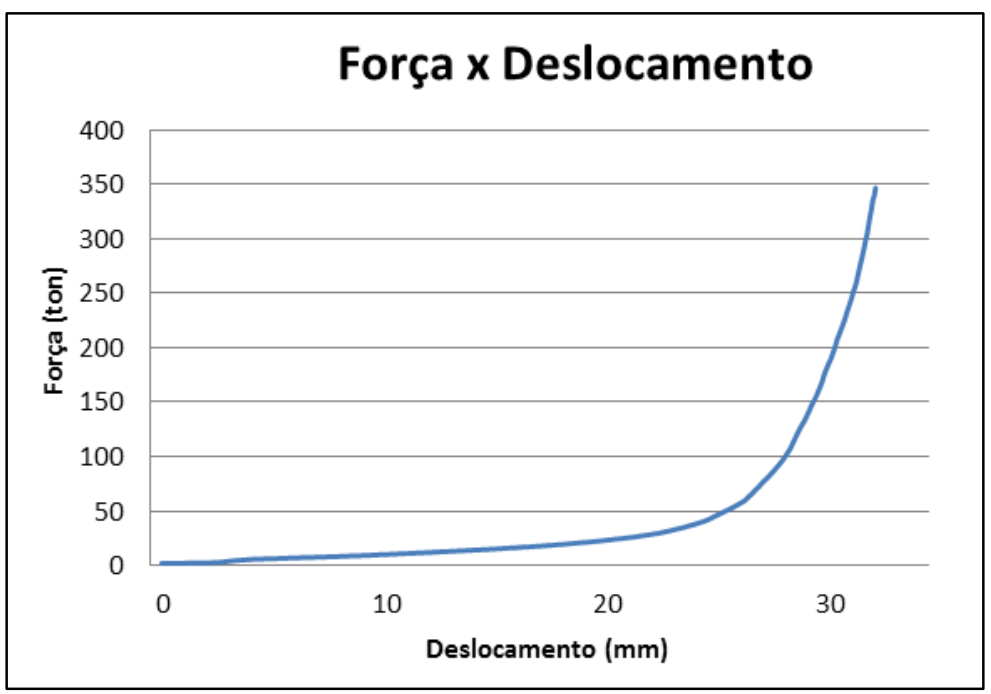

Figura 19. Gráfico da força versus deslocamento obtido no forjamento experimental para billet maciço

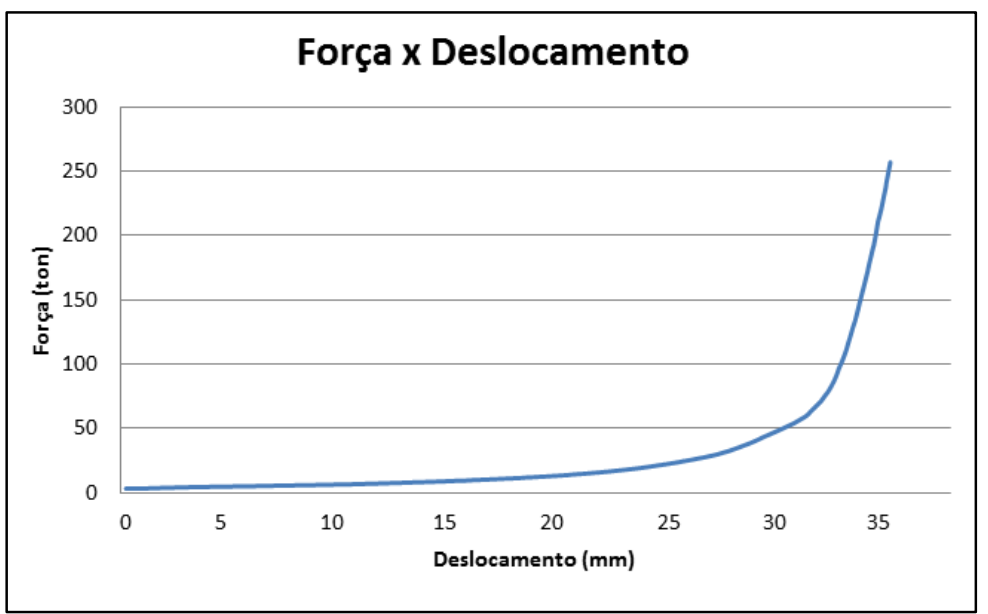

Figura 20. Gráfico da força versus deslocamento obtido no forjamento experimental para billet vazado.

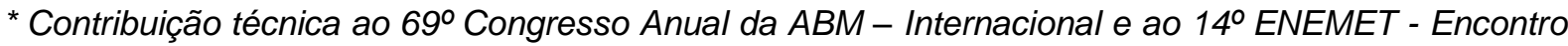
Nacional de Estudantes de Engenharia Metalúrgica, de Materiais e de Minas, 21 a 25 de julho de 2014, São Paulo, SP, Brasil. 


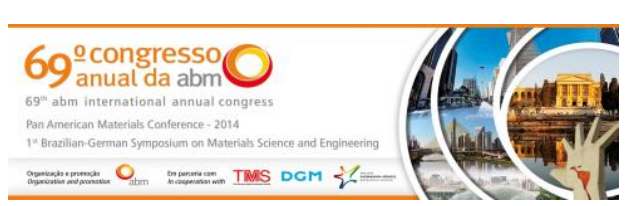

Verifica-se na Figura 19 e na Figura 20 que, à medida que a ferramenta vai se deslocando e forjando o material, é necessário um maior esforço para continuar o forjamento, isso se deve principalmente ao resfriamento do material, devido ao contato com as matrizes, e também pela dificuldade no preenchimento das partes mais delgadas da peça.

Através de uma analise da Figura 21 é possível identificar a diferença da força obtida no experimento, simulação e nos cálculos analíticos. A simulação obteve um menor percentual de diferença na força máxima, para o billet vazado em relação ao experimental. Essa diferença ocorre principalmente pelas desigualdades entre as condições de processamento e as inseridas no software. Mesmo inserindo a curva de Escoamento do AA6351 no software, não se pode garantir que não haja diferença, pois a curva descrita pela literatura não foi obtida da mesma barra que foi usada para confecção dos billets utilizados no forjamento.

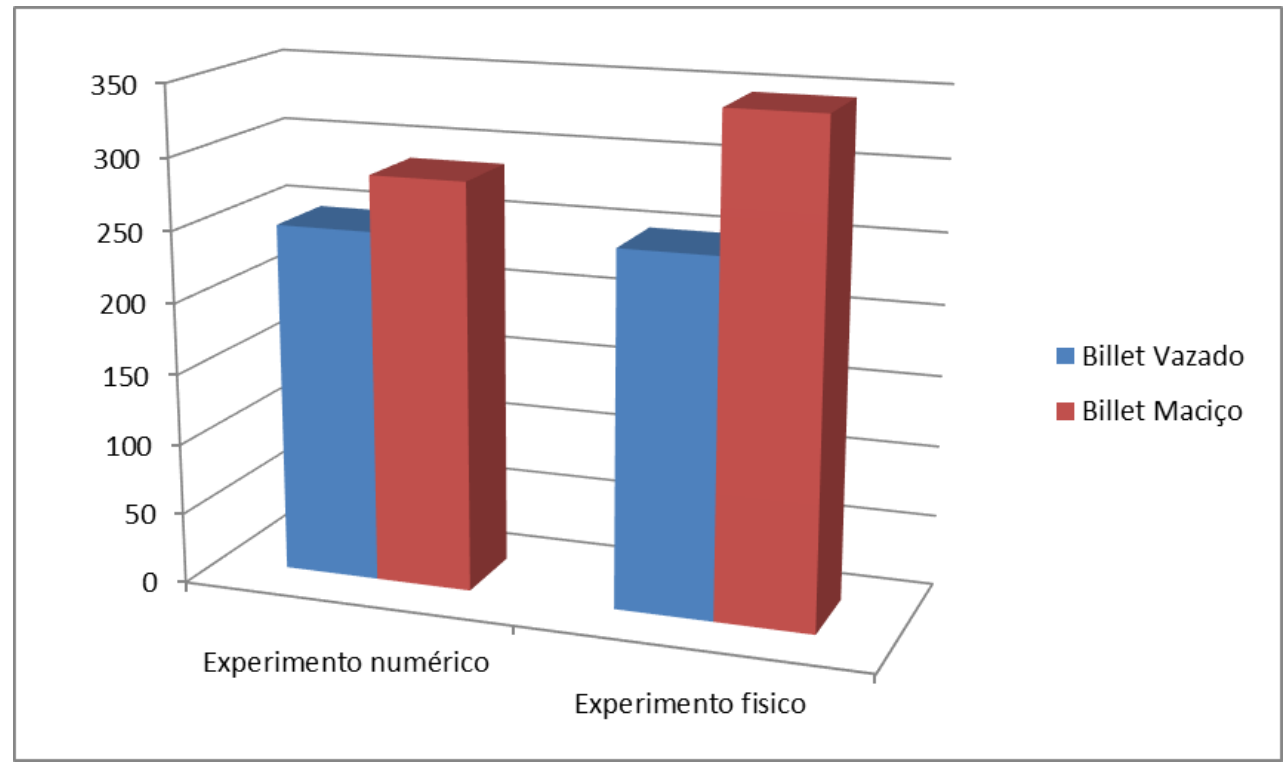

Figura 21. Comparação entre as forças

O forjamento com billet maciço apresentou as maiores forças em todas as situações. A força obtida experimentalmente é a mais elevada, pois foi necessário aumentar o volume do billet para que o material preencha toda a cavidade. Caso contrário, o material escoa para a cavidade de rebarba e não preenche completamente a cavidade. Isso ocorre porque o material apresenta dificuldade em escoar na cavidade superior.

\section{CONCLUSÃO}

O primeiro experimento realizado não pode ser aproveitado, pois os gases retidos na matriz precisam ser eliminados. A simulação numérica não previu este evento e por isso o mesmo só foi identificado durante o experimento. Este problema foi contornado com a inserção de saída de gases na matriz superior e inferior e a partir destas correções pode-se fazer as conclusões almejadas.

Apesar do problema referente a liberação de gases não ter sido detectado pela simulação, pode-se dizer que a simulação numérica computacional se mostrou eficaz para predizer a força necessária para o forjamento das peças, após a fabricação dos furos nas matrizes, para escape dos gases. Quando comparam-se

\footnotetext{
* Contribuição técnica ao 69ำ Congresso Anual da ABM - Internacional e ao 14ํㅡㄹ ENEMET - Encontro Nacional de Estudantes de Engenharia Metalúrgica, de Materiais e de Minas, 21 a 25 de julho de 2014, São Paulo, SP, Brasil.
} 
